\title{
ANÁLISE DO CONSÓRCIO DE PRODUÇÃO E ABASTECIMENTO (CINPRA) DO MARANHÃO À LUZ DOS TEÓRICOS DAS REDES ORGANIZACIONAIS
}

\author{
A. C. R. Costa', A. B. F. M. Nascimento', D. S. Tinôco' \\ ${ }^{1}$ Programa de Pós Graduação em Administração - Universidade Federal do Rio Grande do Norte \\ carolr.costa@yahoo.com.br; alexadministracao@gmail.com; dinahtinoco@uol.com.br
}

Artigo submetido em maio/2011 e aceito em junho/2011

\section{RESUMO}

O presente artigo estrutura-se em uma caracterização dos Consórcios Intermunicipais, seu processo de formação e o suporte teórico que lhe dá fundamentação: o neo-institucionalismo. Conseguinte, a revisão da literatura sobre redes organizacionais com um enfoque para seus mecanismos de imersão social (estrutural, cognitivo, cultural e político). O CINPRA Consórcio Intermunicipal de Produção e Abastecimento, no estado do Maranhão, foi utilizado como foco do estudo por possuir uma experiência de quatorze anos de atuação, tendo suas ações reconhecidas e premiadas nacionalmente, sendo reconhecidas como experiência de prática inovadora na gestão pública. Por meio de uma pesquisa exploratória e da análise de conteúdo, os resultados bibliográficos e documentais caracterizam o CINPRA como uma rede organizacional. Documentos relatórios de gestão, sítios do governo federal, estadual e municipal, além de dados do IBGE e trabalhos acadêmicos foram utilizados como fontes de dados secundários. Por fim, conclui-se que os Consórcios Intermunicipais são um exemplo de rede organizacional e podem ser estudados através dos seus quatro principais mecanismos de imersão social: estrutural, cognitivo, cultural e político.

PALAVRAS-CHAVE: Redes Organizacionais. Consórcios Intermunicipais. CINPRA.

\section{ANÁLISE DO CONSÓRCIO DE PRODUÇÃO E ABASTECIMENTO (CINPRA) DO MARANHÃO À LUZ DOS TEÓRICOS DAS REDES ORGANIZACIONAIS}

\begin{abstract}
This article is structured in a characterization of intermunicipal consortia, the process of training and support that gives theoretical foundation: the institutionalism. Consequently, the review of the literature on organizational networks with a focus to their mechanisms of social embeddedness (structural, cognitive, cultural and political). The CINPRA Intermunicipal Consortium for the Production and Supply in the state of Maranhão, was used as a focus of study by having a experience of fourteen years of operation, an its shares are nationally recognized rewarded and recognized as innovative practice
\end{abstract}

experience in public management. Through and exploratory research and content analysis, the results characterize the bibliographic and documentary CINPRA as an organizational network. Document management reports, websites of federal, state and municipal as well as data from the IBGE and papers have been used as secondary data sources. Finally, we conclude that the inter-municipal programs are an example of organizational network and can be studied through its main mechanisms of social embedddedness: structural, cognitive, cultural and political.

KEY-WORDS: Organizational Networks. Inter-municipal Consortia. CINPRA. 


\section{ANÁLISE DO CONSÓRCIO DE PRODUÇÃO E ABASTECIMENTO (CINPRA) DO MARANHÃO À LUZ DOS TEÓRICOS DAS REDES ORGANIZACIONAIS}

\section{INTRODUÇÃO}

Com o processo de descentralização do Brasil nos últimos anos, sobretudo após a Constituição de 1988, tanto os Estados quanto os Municípios enfrentaram grandes dificuldades na implementação de políticas públicas, bem como no atendimento a determinadas necessidades básicas. Isto ocorreu, principalmente devido à descentralização desordenada, e quando somada às características intrínsecas do federalismo brasileiro geraram um fenômeno chamado 'municipalismo'. Este se caracteriza por aumentar a receita dos municípios e sobrecarregá-lo de demandas de políticas públicas. Isto acarreta deficiências na prestação do serviço público, pois apesar do aumento de receita, os municípios são frágeis financeiramente, sucateados administrativamente e insulados (ABRUCIO, 2005).

E diante desta dificuldade de ação pública, os municípios buscaram em acordos bilaterais e práticas cooperativas uma saída para o dilema. Nesse contexto, os Consórcios Intermunicipais (fenômeno de articulação intergovernamental praticado desde o século XIX em São Paulo) ganham mais ênfase por se tratar de uma ação cooperativa que viabiliza as ações públicas diante de problemas que Municípios e Estados não poderiam resolver sozinhos (CRUZ, 2002).

Essa incapacidade de resolução de problemas agindo isoladamente que remete aos conceitos de redes organizacionais. A proposta das redes organizacionais parte de um ideal de cooperação e solidariedade entre várias organizações. Cooperação ocorre quando um grupo com domínio de um problema se envolve num processo interativo, usando papéis, geralmente, normatizados para solucionar o problema (GRAY; WOOD, 1991).

Portanto, pode-se afirmar que os consórcios intermunicipais são, fundamentalmente, redes organizacionais, pois a característica base de ambos os fenômenos (redes organizacionais e consórcios intermunicipais) partem de uma relação de cooperação mútua com foco para resolução de problemas ou implementação de ações coletivas. Assim, o problema que instiga esse artigo é: quais as características do Consórcio Intermunicipal de Produção e Abastecimento (CINPRA) que podem ser identificadas nos conceitos de redes organizacionais

O CINPRA foi escolhido como objeto de estudo por possuir uma considerável experiência de quatorze anos de atuação. Tendo suas ações reconhecidas e premiadas três vezes em concursos de caráter nacional, sendo um prêmio pelo SEBRAE-Nacional (Prefeito empreendedor - Prêmio Mario Covas); e dois prêmios (1999 e 2001) pelo Programa Gestão e Cidadania (PGPC), parceria da FGV, da Fundação Ford, e do BNDES, reconhecendo-o como experiência de prática inovadora na gestão pública.

As ações estão registradas nos principais bancos de dados e registro de boas práticas de políticas públicas no Brasil, por exemplo, no Instituto Polis e na base de dados sobre Consórcios Públicos da Presidência da República. Além de suas práticas de sucesso, a localização do consórcio também motivou a escolha deste caso, pois o Maranhão, assim como outros estados do nordeste, teve um processo de formação histórica baseada em uma visão 
localista na qual os municípios se atêm somente aos seus próprios interesses, configurando assim um insulamento na gestão (soma-se a isto o dilema das oligarquias, coronelismos e centralidade de gestão, típicos da cultura brasileira). Sendo assim, o CINPRA se mostra como uma ação pública inovadora e ousada para esta região, sobretudo no que diz respeito à prática de parcerias e ação coletiva na gestão pública.

Com base nessa ideia, o presente artigo caracterizará os Consórcios Intermunicipais, seu processo de formação e o suporte teórico que the dá fundamentação: o neoinstitucionalismo. Conseguinte uma revisão da literatura sobre redes organizacionais com um enfoque para seus mecanismos de imersão social (estrutural, cognitivo, político e cultural). Os delineamentos metodológicos que conduziram a pesquisa, logo após, a apresentação teórica e por fim, serão analisados os resultados bibliográficos que caracterizam o CINPRA como uma rede organizacional.

\section{CONSÓRCIOS INTERMUNICIPAIS}

Os consórcios intermunicipais são uma prática de gestão relativamente antiga, sendo mencionada na Constituição paulista de 1891 e nas legislações de 1937 e 1967, sendo suprimida na Emenda Constitucional de 1969. Com o processo de federalização e corrente descentralização de responsabilidades aos poderes governamentais ocorrido no Brasil nos últimos 50 anos do século XX, surge paralelamente um anseio dos governos municipais em trabalhar cooperação entre si, bem como entre os outros atores sociais. Ou seja, um movimento em que a ação pública (entes políticos conjuntamente com a sociedade civil) busca por soluções em conjunto (COSTA FILHO, 1955; ALMEIDA, 1958; TAVARES, 1977 apud LIMA, 2000).

Esse movimento tem sido fundamental para o surgimento de 'novos arranjos' institucionais na esfera pública, que em alguns casos se configuram através de redes de relações entre governos, municípios, e setores, na construção de uma nova governança. Tais redes são estabelecidas através de associações, convênios, consórcios intermunicipais, entre outros (FARAH, 2001).

Dentre essas práticas de redes, a formação dos Consórcios destaca-se por não obedecer, necessariamente, a uma ordem pré-estabelecida, e sim aos interesses dos municípios consorciados de uma dada região, que entre si determinam as prioridades e os modos de formação. Os consórcios intermunicipais podem atender a diversos fins, a exemplo: melhoramento de estradas; assistência de saúde; esgotamento de resíduos sólidos; saneamento básico; abastecimento de produção local; e outros.

Em termos etimológicos, consórcio vem do latim consortiu e implica a ideia de associação. Essa ideia de cooperação tem permeado dentre os estudos acadêmicos como estratégia de se criar uma força interna com maior sustentação. Nesse diapasão, os consórcios intermunicipais compactuam-se com as ideias de associação e cooperação, uma vez que eles partem com o objetivo de articular políticas públicas com as delimitações territoriais. Assim, as políticas públicas têm a possibilidade de "setorializar" suas ações no âmbito dos serviços básicos sociais. 
Na definição de Torres (1995): 'Consórcio' implica a ideia de associação, ligação, união e, no âmbito das relações intermunicipais, nada mais apropriado do que a formação de entidades visando o estudo, o acompanhamento, o diagnóstico das soluções que, geralmente, envolvem municípios 'limítrofes' e com problemas que se identificam numa ordem cada vez mais crescente em função de forte demanda dos administrados.

Já Spink (2006) traz o conceito de Consórcio Intermunicipal para um viés organizacional. Para o autor, esse termo significa uma entidade que é composta por diversos municípios para implementar ações conjuntas, nas quais esses municípios não conseguiriam agir sozinhos. O autor sustenta ainda a ideia do Consórcio como uma organização com personalidade jurídica e financeiramente autônoma.

Vaz (1997, p. 26), por sua vez, define consórcio como "entidade que reúne diversos municípios para a realização de ações conjuntas que se fossem produzidas pelos municípios, individualmente, não atingiriam os mesmos resultados ou utilizariam um volume maior de recursos". Para Cruz (2002) os Consórcios Intermunicipais são associações através de acordos entre as entidades públicas que partem de um interesse comum, utilizando-se de recursos humanos e materiais que cada um dispõe.

Com base no relato dos autores, infere-se que os Consórcios são instituições nas quais os atores políticos decidem cooperar entre si para solucionar problemas de comum interesse e em áreas específicas, com o objetivo de atender às demandas locais. Atuando em áreas que sozinhos, ou não conseguiriam ou despenderiam mais gastos com tempo e energia.

No processo de formação dos consórcios intermunicipais, os estudos dos neoinstitucionalistas são fonte de análise comparativa, resguardadas suas devidas contextualizações. Há três abordagens que caracterizam o quadro de ideias neoinstitucionalistas. O neo-institucionalismo é uma escola que discorre sobre análises da economia a partir da evolução das instituições (NORTH, 1990). São elas: Institucionalismo Histórico, Institucionalismo da Escolha Racional e Institucionalismo Sociológico.

Todas as três abordagens surgem para apresentar medidas de ação institucional que trazem resultados frente às demandas sociais, bem como ocorre nos consórcios intermunicipais cujo objetivo central é satisfação de um interesse social coletivo.

Essa corrente, portanto, consolidou-se na ciência política nos anos 70 e 80 como tentativa de oferecer respostas, que as abordagens behavioristas pareciam incapazes de responder. Todas buscam elucidar o papel desempenhado pelas instituições na determinação de resultados sociais e políticos (HALL; TAYLOR, 2003).

Segue então uma tentativa de explicar, ainda que brevemente, as principais características de cada escola do neo-institucionalismo. O institucionalismo histórico situa-se em torno de uma crítica ao paradigma funcionalista que tinha o Estado como figura neutra. Eles tinham como concepção o fato de que o conflito entre grupos rivais pela apropriação de recursos escassos era a centralidade da vida política. Ou seja, o Estado era um grupo de instituições complexas capaz de estruturar a natureza e os resultados dos conflitos entre grupos (EVANS, 1985 apud HALL; TAYLOR, 2003). 
Os institucionalistas históricos se posicionavam favoráveis às assimetrias de poder. Para eles, as instituições repartem o poder de forma desigual e reforçam que há grupos sociais que são "perdedores" e outros que são "ganhadores". Assim ao invés de basear seus cenários sobre a liberdade dos indivíduos de firmar contratos, eles preferem postular um mundo onde as instituições conferem a certos grupos um acesso desproporcional ao processo de decisão (HALL; TAYLOR, 2003).

Para North (1990) as instituições são as regras da sociedade que age através das organizações, e tais ações, segundo a Teoria da Escolha Racional, são feitas a partir de maximização do benefício próprio. Assim o neo-institucionalismo através da teoria da escolha racional contribuem para explicar os fatores que levam os indivíduos a agirem. No caso dos consórcios, ela pode ajudar a explicar o que leva os municípios a aderirem a esse tipo de arranjo.

Segundo Kaufman (1998, p.12) "essa escola considera os políticos como principais 'provedores' de políticas públicas e dos meios administrativos para implementá-los." Essa colocação pode ser justificada pelos fundamentos do institucionalismo da escolha racional, a busca pela escolha ótima e a centralidade das ações. O institucionalismo da escolha racional tende a ser mais aplicável em situações estáveis, com regras do jogo bem claras e onde há um relativo conhecimento das preferências dos outros atores (KAUFMAN, 1998).

Ainda nesse diapasão, essa escola sustenta a ideia de previsibilidade dos comportamentos dos demais atores e agem de modo completamente utilitário para maximizar a satisfação de suas preferências. Assim, pensando em satisfazer suas próprias necessidades, irão produzir um resultado sub-ótimo para a coletividade. Para isso, os teóricos enfatizam a ideia de interação estratégica na determinação das situações políticas, ou seja, o comportamento de um autor é determinado por um cálculo estratégico que é influenciado pelas expectativas do ator relativas ao comportamento dos outros atores (HALL; TAYLOR, 2003).

Portanto, essas duas escolas de pensamento neo-institucionalistas colocam como ator principal o Estado na formulação da ação pública, seja essa ação através do processo histórico, seja pela escolha racional.

O "institucionalismo sociológico" é a escola da ciência política que se correlaciona com os estudos de redes organizacionais, e isso se deve ao caráter substantivo nas formas e procedimentos institucionais através de práticas culturais. Dessa forma, segundo Hall e Taylor (2003) as ações mais burocratizadas podem ser consideradas como práticas culturais.

O fato de considerar os aspectos culturais leva a inserir o homem como ator que interfere nas ações institucionais, e isso relativamente difere essa escola das anteriores, como diz Kaufman, 1998:

Para as perspectivas, a da economia política [institucionalismo histórico] e a da escolha racional, as instituições são sistemas de regras que controlam o modo como os atores buscam atingir metas exógenas - renda, poder político, etc. Na sociologia institucional, o comportamento humano está "inserido" na matriz de organizações e relações informais que fornecem filtros fundamentais, através dos quais a realidade é interpretada e as identidades básicas e preferências são criadas (p.57). 
Aqui fica em destaque a importância dos demais atores sociais, fato que corrobora com a ideia de Spink (2006), ao diferenciar os consórcios das regiões metropolitanas, afirmando que estas últimas partem de uma relação de cima para baixo e a associação é obrigatória. Já no caso dos consórcios, a relação é de baixo para cima e os atores se arranjam de forma voluntariada. Dessa forma, Spink (2006) diferencia consórcios de regiões metropolitanas a partir do ator que propõe o arranjo, sendo top-down no caso das regiões metropolitanas e button-up no caso dos consórcios.

Juridicamente, os doutrinadores conceituam 'consórcios' como acordos celebrados entre entes do mesmo nível de governo para o êxito em atividades de interesse comum (MEDUAR, 1996; PIETRO, 1999; MEIRELES, 1994 apud SANTOS, 2008).

Conforme o Quadro 01 a seguir, os consórcios intermunicipais percorreram um árduo caminho até a legalização em 2005.

Quadro 01: Linha do Tempo do processo Legal de formalização dos consórcios. (1981-2007)

\begin{tabular}{|c|c|}
\hline Período & Evento \\
\hline De 1891 a 1937 & $\begin{array}{l}\text { Os consórcios eram contratos celebrados entre municííos cuja eficácia } \\
\text { dependia de aprovação do Estado, ou entre Estados na dependência de } \\
\text { aprovação da União. }\end{array}$ \\
\hline 1937 & $\begin{array}{l}\text { A Constituição reconhece que os consórcios (associações de municípios) } \\
\text { são pessoas jurídicas de direito público, mas o Estado Novo não - período } \\
\text { ditatorial e centralizador que não respeitava a autonomia dos entes } \\
\text { federados. }\end{array}$ \\
\hline 1961 & $\begin{array}{l}\text { É criado o Banco Regional de Desenvolvimento Econômico da Região Sul } \\
\text { - BRDE, a primeira autarquia interfederativa brasileira. }\end{array}$ \\
\hline De 1964 a 1988 & $\begin{array}{l}\text { Surgem os consórcios administrativos, meros pactos de colaboração sem } \\
\text { personalidade jurídica - período de repressão política. }\end{array}$ \\
\hline De 1988 até hoje & $\begin{array}{l}\text { Criação de inúmeros consórcios intermunicipais. Em 2001, só na área da } \\
\text { saúde, haviam } 1969 \text { municípios consorciados. }\end{array}$ \\
\hline Em 1998 & $\begin{array}{l}\text { A Emenda Constitucional } n^{0} 19 / 98 \text { alterou a redação do art. } 241 \text { da } \\
\text { Constituiçãão e introduziu os conceitos de consórcio público e de gestão } \\
\text { associada de serviços públicos. }\end{array}$ \\
\hline 2005 & $\begin{array}{l}\text { Lei de Consórcios Públicos - Lei n² 11.107/05. Alteração nas Lei de } \\
\text { Licitação e de Consórcios. }\end{array}$ \\
\hline 2007 & Decreto 6.017/07 regulamenta a Lei de Consórcios. \\
\hline
\end{tabular}

Fonte: CALDAS, 2007.

Legalmente, os consórcios intermunicipais foram regulamentados somente em 2005 com a Lei 11.107, a qual legitima a criação de consórcios intermunicipais, bem como normatiza as exigências de criação dos mesmos. Na referida lei, o caput já estabelece o que é unânime entre os autores da área: que os consórcios intermunicipais têm como prerrogativa o 
interesse comum para que seja criado. Dentre as disposições a lei ainda diz:

$\S 1$ o O consórcio público constituirá associação pública ou pessoa jurídica de direito privado.

§ 20 A União somente participará de consórcios públicos em que também façam parte todos os Estados em cujos territórios estejam situados os Municípios consorciados (BRASIL, 2010, p. 203).

Conforme supracitado, os consórcios intermunicipais são novas formas de gestão que proporcionam a realização de ações que uma única prefeitura não conseguiria resolver sozinha. Entre essas ações, pode-se citar o aumento da capacidade de realização de políticas públicas (ao se consorciar, os municípios podem implementar outras ações); a maior eficiência do uso de recursos públicos, já que recursos são novamente auditados, desta vez pela administração do consórcio; aumento do diálogo, pressão e negociação dos municípios; e o aumento das transparências das decisões públicas.

É, portanto, um arranjo viável para a boa prestação dos serviços públicos municipais, e essa articulação pode ser fundamental para a formação de uma rede interinstitucional de cooperação e ajuda mútua. Assim, a relação horizontal e 'solidária' se sobrepõe à relação vertical e competitiva.

Alguns fatores podem surgir como limitação ao funcionamento dos consórcios, tais como interesse político partidário; planejamento de curto prazo; e não formalização de direitos e deveres. Os quais podem ser trabalhados e melhorados conforme a ação profissional dos atores envolvidos.

\section{REDES ORGANIZACIONAIS}

Segundo Rodrigues (2006), a palavra "rede" vem do latim retis e significa teia, entrelaçamento de fios que formam uma espécie de tecido de malha aberto. Através do observado nos estudos sobre o tema, esse termo vem ganhando novos significados com o passar dos anos, entre eles o que será trabalhado no presente artigo: a relação de pessoas e organizações que mantêm contato entre si com um objetivo comum ou com objetivos distintos, mas congruentes.

O pressuposto da análise de redes é o de que as ações econômicas estão imersas socialmente, ou seja, as relações sociais determinam a ação econômica dos atores - também conhecido como o princípio da imersão social. Assim, pode-se afirmar também que as relações econômicas estão imersas na estrutura social (POLANYI, 2000; GRANOVETTER, 1985). Urge lembrar que o pensamento de Polanyi (2000) era de que a estrutura econômica estava imersa na estrutura social e a isso ele conceitua como "imersão social", porém com o decorrer do tempo essa imersão se reverteu e se constatou mudanças sociais voltadas para um mercado 'auto-regulável'. Logo, a 'imersão social' não significa que a estrutura econômica deva se inserir na estrutura social como se fosse algo inédito, mas sim 'retornar' à sua devida posição de origem, ou seja, imersa socialmente. 
Granovetter (1985), que remonta a Polanyi (2000), define a imersão social como residindo em algum lugar entre a ação sub e sobressocializada. Sua preocupação está no fato de que é necessário estabelecer um adequado elo entre as teorias de nível macro e nível micro. Para isso, é necessário ter um completo entendimento dessas relações sociais nas quais as ações econômicas estão imersas.

Polanyi (2000) defende que a sociedade, antes de estar centrada no mercado, mantinha valores centrados na reciprocidade, redistribuição e domesticidade. Negando então a centralidade no mercado como algo naturalmente evoluído da condição humana. Seu argumento era de que o ganho e o lucro assumiram um papel excessivamente central na sociedade capitalista de tal forma nunca ocorrido na história. Assim, considerando que as ações econômicas estão imersas na estrutura social, esta afeta as ações econômicas. A partir do conceito de imersão social, Zukin e DiMaggio (1990) apontam quatro mecanismos de imersão, mostrando assim diferentes perspectivas da imersão social. Estes quatro mecanismos são: estrutural, cognitivo, político e cultural, que serão trabalhados a seguir.

\subsection{Mecanismo de Imersão Social Estrutural}

No mecanismo de imersão estrutural é unânime, na categorização, os tipos de laço (GRANOVETTER, 1973), a qualidade dos relacionamentos (UZZI, 1997) e posição dos atores na rede, quanto à centralidade de cada um ou periferia (BURT, 1992).

A primeira categorização, proposta por Granovetter (1973), o autor metaforiza a relação entre os atores das redes através do termo 'laço', classificando em laço fraco e laço forte. Os laços fracos significam relações mais díspares entre os atores, enquanto os laços fortes significam estreitamentos entre os atores. Pode-se ainda fazer inferências quanto ao fluxo de informação entre os atores de acordo com o tipo de laço, nos fortes a troca de informação é mais intensa e nos fracos são menores.

Porém, a intensidade desses laços pode determinar certo comodismo em relação às inovações, pois quanto mais forte for o laço, menores são as possibilidades que os atores têm de se desprenderem do consciente coletivo tácito (ou explícito) e se permitirem a inovações.

Para Uzzi (1997) a qualidade dos relacionamentos pode ser observada no compartilhamento de informações. São consideradas satisfatórias quando há abertura para constantes e fidedignas trocas de dados, nas quais cada ator possui direitos de expor suas ideias. Quando esta troca de dados é limitada ou desigual, o relacionamento pode ser insatisfatório. Não se trata de mais ou menos informações, e sim da amplitude e profundidade dos dados.

A posição do ator na rede pode ser identificada pelo grau de relevância entre os demais e pelo volume de informações que ele atrai. Assim, quando um ator exerce forte influência sobre os demais nas decisões, nos objetivos e direcionamentos da rede, pode-se dizer que tal ator está em uma posição central. Consequentemente, quando o ator não exerce tal influência, ele está em uma posição periférica (BURT, 1992). 


\subsection{Mecanismo de Imersão Social Cognitivo}

O mecanismo de imersão cognitiva traz a discussão sobre os processos mentais (individuais ou coletivos) e trata de como as regularidades estruturais do processo mental limitam Ou condicionam o exercício da ação econômica (DACIN; VENTRESCA; BEAL, 1999). Esses elementos de imersão postulam, portanto, a limitação da racionalidade humana tanto individual quanto coletiva, assim o homem não dispõe de capacidade absoluta de fazer a escolha ótima, e sim a escolha satisfatória (SIMON, 1967).

Logo, há duas abordagens nesse quesito, um trata do processo mental e sua consequente limitação na racionalidade individual e econômica. E outra que se centra na maneira como a cognição social mais ampla impacta na ação organizacional (DACIN; VENTRESCA; BEAL, 1999).

\subsection{Mecanismo de Imersão Social Cultural}

A imersão cultural diz respeito à forma como os entendimentos coletivos compartilhados afetam as estratégias econômicas e os processos organizacionais, podendo afetar as estruturas nas quais as ações ocorrem, bem como constranger as forças de mercado. Apesar de cultura ser uma manifestação local, ela pode ser uma força mais ampla de influência nas ações da rede (não determinante) (BALDI, 2004).

\subsection{Mecanismo de Imersão Social Político}

Quanto ao mecanismo de imersão política, analisam-se as assimetrias de poder entre atores, que afetam fontes e meios da ação econômica. O comportamento econômico politicamente imerso é moldado pela disputa de poder entre atores como Estado e classes sociais. Essas assimetrias dão suporte para que uns atores consigam estabelecer suas decisões e conquistar o apoio dos demais atores (BALDI, 2004).

Esse mecanismo propõe uma interação entre os atores tanto por persuasão como por coação, as ações da rede sofrem diretamente com isso, principalmente quando há grande centralidade de poucos atores (pertencentes ao mercado ou não). Os estudos sobre esse mecanismo buscam compreender como as diferenças de poder conseguem determinar as ações da rede (ZUKIN; DIMAGGIO, 1990 apud DACIN; VENTRESCA; BEAL, 1999).

Nos estudos sobre consórcios intermunicipais é prevista certa simetria de poder, ainda que apenas formalmente. Porém, na prática, mesmo com uma administração colegiada (como prevê a Lei dos Consórcios 11.107/2005), há superioridade de poder em alguns casos. A esse respeito o leitor verá adiante a comprovação teórica com base nos autores específicos da área. As diferenças de poder conseguem suscitar diversos fatores como a posição geográfica, capacidade financeira, articulação política, interesse partidário. 


\section{PROCEDIMENTOS DE PESQUISA}

A fim de alcançar o objetivo de esclarecer os conceitos de Consórcios Intermunicipais e de Redes Organizacionais e, assim, analisar o CINPRA, este artigo utilizará uma pesquisa exploratória que, segundo Mattar (2005), tem como objetivo criar um aprofundamento teórico sobre a relação teórica na discussão. Para Vergara (2004) a pesquisa exploratória proporciona maior proximidade com o tema em estudo e visa fornecer clareza com o conteúdo, a autora afirma ainda que neste tipo de pesquisa seja utilizado como método o levantamento bibliográfico e documental.

Por se tratar de uma pesquisa que busca construir uma concepção, ainda que essencialmente teórica, este trabalho requer uma abordagem qualitativa. Buscando descrever relações conceituais de uma realidade socialmente construída e não determinística (TRIVINOS, 1995; SCHWANDT, 2006).

Para tanto, utilizou-se como método o estudo de caso, especificamente, o CINPRA por se tratar de uma experiência de resultados positivos para a região e reconhecida por institutos renomados de pesquisa. A técnica utilizada para a coleta de dados foram: pesquisa bibliográfica e documental. Na etapa bibliográfica foram coletados artigos acadêmicos, teses e livros correlatos. Para a captura dos dados documentais, a pesquisa se limitou aos dados secundários, tais como: relatório do prêmio Gestão Pública e Cidadania, da Fundação Getúlio Vargas de 1999 e 2001 (edições em que o CINPRA foi premiado); Relatório do "Projeto Conexão Local - Ano I", também organizado pela FGV em 2005; e reportagens da imprensa local. Também foram utilizados dados do IBGE, sítios do governo federal e estadual, bem como da prefeitura de São Luís.

Uma vez coletados os dados, as informações foram analisadas pela técnica de análise de conteúdo, tentando identificar ausência ou presença de certas características (BARDIN, 1997; QUIVY; CAMPENHOUDT, 1998). As análises se balizaram por categorias analíticas que estiveram sempre relacionadas com o problema da pesquisa, bem como com o objetivo geral, dessa forma define-se 04 (quatro) dimensões de análise: (D1) Mecanismo de Imersão Social Estrutural; (D2) Mecanismo de Imersão Social Cognitivo; (D3) Mecanismo de Imersão Social Cultural; e (D4) Mecanismo de Imersão Social Político.

Tais dimensões receberam definições constitutivas, não com o objetivo de exaurir a discussão, mas para conduzir o leitor durante as relações conceituais na análise do caso. Estes procedimentos metodológicos atendem aos objetivos da pesquisa no instante em que esta se limita ao estudo exploratório do tema e, portanto, é uma inédita e primeira aproximação entre os estudos de consórcios intermunicipais e redes organizacionais.

\section{ANÁLISE DO CINPRA À LUZ DAS REDES ORGANIZACIONAIS}

O Consórcio Intermunicipal de Produção e Abastecimento (CINPRA) funciona no Estado do Maranhão e é composto por 17 municípios. Seu principal interesse é garantir o suprimento de produtos-base rural de consumo dentre os municípios que o compõe. Sua criação decorreu dentro do contexto político criado ainda por Fernando Collor de Melo, então Presidente da 
República, que em ocasião de seu mandato extinguiu a Empresa Brasileira de Assistência Técnica e Produção Rural (EMBRATER), deixando a critério dos Estados a decisão de continuar, ou não, atuando nessa área, através de empresas estaduais conhecidas como "EMATER" (BARBOZA; AROUCA, 2002).

No Maranhão, a situação foi mais agravante, pois além de extinguir a Emater local, a governadora que cumpria o mandato no ano de 1997 decidiu extinguir todas as 18 secretarias e diversos órgãos da administração indireta, incluindo a Empresa Maranhense de Pesquisa Agropecuária (EMAPA). No lugar das secretarias ela criou gerências gerais, das quais a subgerência de Agricultura estava vinculada (TRINDADE, 1999).

Visto esse ambiente político-administrativo, a secretaria municipal de produção e abastecimento de São Luís promoveu diversos encontros com demais prefeitos das regiões próximas a $270 \mathrm{~km}$ de raio, bem como com autoridades ligadas a instituições de agricultura e de crédito rural. Desses encontros, surgiu a proposta de criar o CINPRA, que em sua carta de intenções estabeleceu como objetivos: a) garantir a assistência técnica para pequenos produtores rurais; b) melhorar o nível de renda desses produtores; c) diminuir a importação de produtos hortifrutigranjeiros (CALDAS, 2007).

Nesta etapa de criação do CINPRA pode-se perceber uma construção button-up, pois no instante em que os municípios se percebem frente a um problema específico de abastecimento eles buscam auto-organização como solução. É fato que isto foi um movimento que partiu inicialmente de um único ator, do Secretário de Produção e Abastecimento de São Luís, mas ele sozinho não teria conseguido resolver o problema sem o envolvimento dos outros atores. Os outros municípios foram levados a aderir ao consórcio, tanto pela dificuldade de produção e abastecimento dos produtos rurais como pela confiança na articulação em rede através do consórcio (BARBOZA; AROUCA, 2002).

Esses laços foram possíveis porque a imersão social cognitiva foi conquistada. A imersão cognitiva aqui ressaltada é aquela não só individual que parte dos mecanismos mentais de decisão de cada ator, e sim dos mecanismos coletivos mais amplos e de ação organizacional (DACIN; VENTRESCA; BEAL, 1999).

O CINPRA, por sua vez, surgiu de ação inédita no Maranhão, porém a articulação em torno do que os neo-institucionalistas sociológicos chamam de comportamento estratégico prático foi fundamental para conquistar a confiança dos demais municípios, pois mesmos os que não tinham tanto conhecimento sobre os reais objetivos e operacionalidade do consórcio foram convencidos com os primeiros resultados positivos (CALDAS, 2007).

No que se refere ao estado do Maranhão, pode-se afirmar que este possuía características diferentes dos demais estados nordestinos, tais como água abundante e vegetação atlântica fato que se justifica pela proximidade da região norte. Segundo dados do IBGE (2010), mais de $40 \%$ de sua população vivem na zona rural, somente na década de 90 sua população passou a ser predominantemente urbana, concentrada principalmente na ilha de São Luís e em mais três municípios (Passo do Lumiar, São José do Ribamar e Raposa). Entretanto, ao adentrar no interior do estado nota-se a predominância das atividades rurais e a carência de serviços básicos. 
Há uma forte dependência de recursos federais e estaduais nos municípios maranhenses, no mais os agricultores se sustentam do que a própria terra pode lhes oferecer. E apesar do grande peso da agricultura na economia maranhense, da quantidade enorme de terras agricultáveis e do grande número de pessoas que vivem da agricultura, o Maranhão ainda traz de outros Estados mais de $80 \%$ da produção de hortifrutigranjeiros para abastecer a capital. E o CINPRA tem nesse fato seu grande desafio, para tanto a prefeitura de São Luís conseguiu reunir 13 municípios (nos anos seguintes ingressaram mais quatro municípios, totalizando dezessete) ao seu entorno em prol de sanar essa deficiência de abastecimento (BARBOZA; AROUCA, 2002).

Na tabela 1, a seguir, pode-se visualizar o nome dos referidos municípios, assim como sua população:

Tabela 1 - Municípios consorciados por população.

\begin{tabular}{r|l|r}
\hline No & \multicolumn{1}{|c|}{ Município } & Número de Habitantes \\
\hline 1 & Anapurus & 10.413 \\
\hline 2 & Axixá & 10.107 \\
\hline 3 & Cantanhede & 14.445 \\
\hline 4 & Chapadinha & 70.537 \\
\hline 5 & Humberto de Campos & 21.879 \\
\hline 6 & Icatu & 24.432 \\
\hline 7 & Matões do Norte & 7.700 \\
\hline 8 & Morros & 17.077 \\
\hline 9 & Pirapemas & 21.664 \\
\hline 10 & Presidente Juscelino & 7.321 \\
\hline 11 & Rosário & 37.920 \\
\hline 12 & Santa Inês & 85.701 \\
\hline 13 & São João Batista & 12.281 \\
\hline 14 & São Luís & 997.098 \\
\hline 15 & Santa Rita & 31.033 \\
\hline 16 & Viana & 49.348 \\
\hline 17 & Vitória Mearim & 30.819 \\
\hline Fonte: IBGE, 2009 &
\end{tabular}

A partir da dimensão D1 (Mecanismo de Imersão Social Estrutural), pode-se observar a presença de uma relação de interdependência entre os atores consorciados do CINPRA, inerente à própria função do consórcio, essa rede de abastecimento possui fortes laços estruturais. Os municípios possuem estreitas ligações, buscando não só suprir com a produção, como também capacitar técnicos para o acompanhamento da produção. Há certa centralidade do município de São Luís e influência desse ator frente aos demais, devido a questões políticas e a outras questões próprias de uma capital, como facilidade de recursos, atratividade populacional e carência de zona rural própria (TRINDADE, 1999).

Mesmo com a centralidade do município de São Luís e influência desse ator frente aos demais, é visível a formação de laços estreitos entre os municípios consorciados, fato que 
pode ser justificado pela proximidade em que se localizam tais municípios. Isto pode ser identificado na Figura 02 a seguir, que mostra o estado do Maranhão e a localização dos municípios envolvidos.

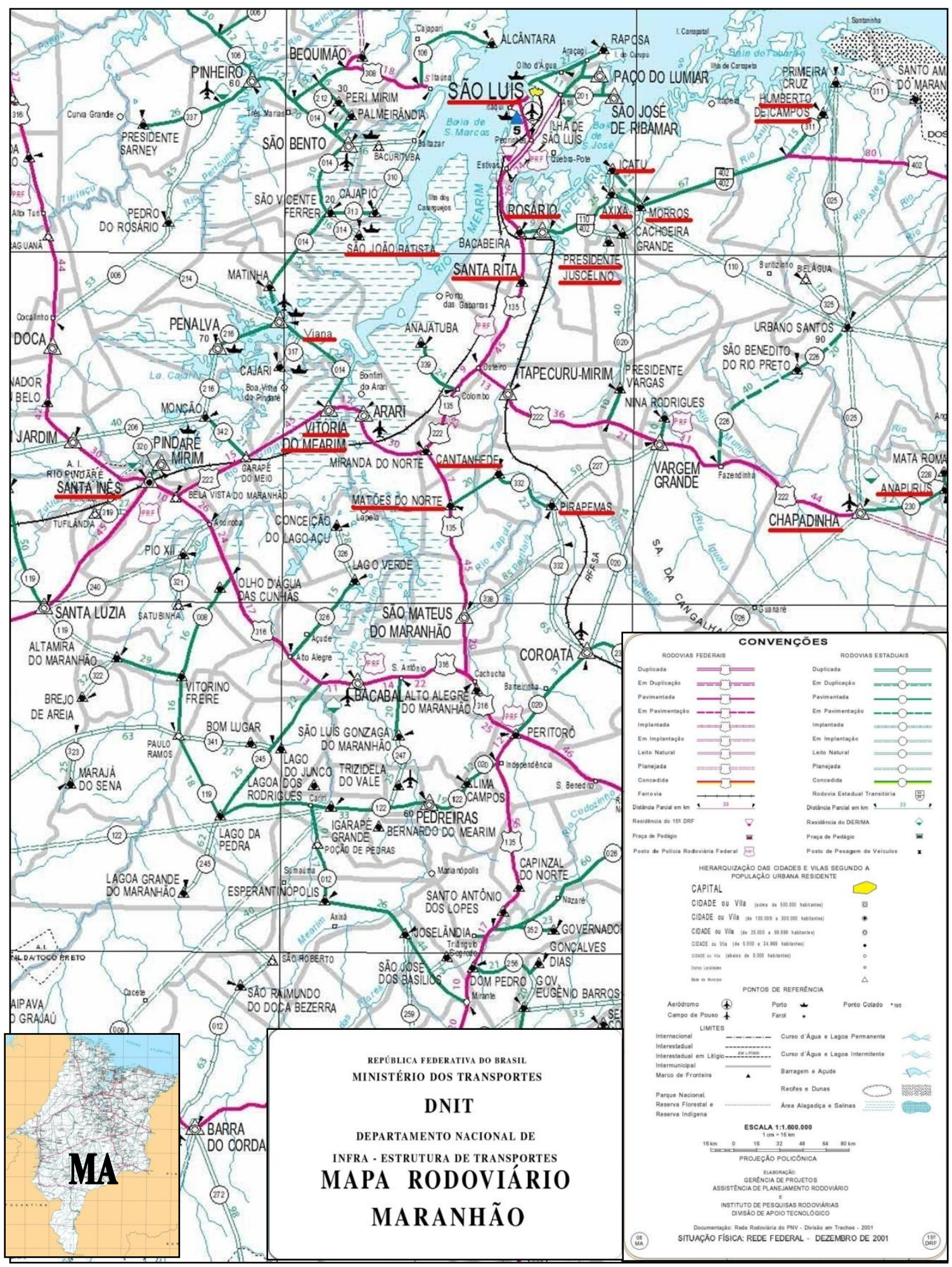

Figura 02 - Mapa do Estado do Maranhão. Fonte: BRASIL, 2011. 
A dimensão D2 (Mecanismo de Imersão Social Cognitivo) pode ser observada no processo de formação do CINPRA, especificamente nos fatores que levam à decisão de aderir ou não ao consórcio. O contexto local que motivou a formação do CINPRA (baixa produção agrícola e grande importação de outros estados) alertou os idealizadores deste projeto para a oportunidade de reduzir esse problema de forma unida e, assim, gerar desenvolvimento para a região. Esse discurso passou a fazer parte de um consciente coletivo entre os prefeitos da região, logo a matriz racional e cognitiva destes atores foi influenciada pelo vislumbre de gerar emprego, renda, e desenvolvimento, através de uma ação coletiva. Isto fica evidente nas palavras do ex-secretário executivo do CINPRA em entrevista ao Jornal da Embrapa "Pesquisa Estadual em Foco":

\begin{abstract}
Um município sozinho é fraco. Unidos na região todos se fortalecem. O campo precisa das cidades, mas as cidades precisam do campo. Não pode haver uma cidade rica, com um campo miserável ao seu redor. Da mesma forma não haverá cidadepólo, forte e sustentável, rodeadas por cidades periféricas estagnadas, dependentes de ações e decisões de fora e que abandonem à própria sorte o seu parque produtivo essencial. O lema do CINPRA é "Prefeituras Unidas ajudando o Maranhão a produzir." (PESQUISA ESTADUAL EM FOCO, 2001, p. 4).
\end{abstract}

Uma vez criado e consolidado o consórcio, seus integrantes passaram a compactuar de objetivos comuns. Mesmo que possuíssem interesses diferentes, os consorciados estavam ligados por um fio comum que era a necessidade de aumentar a produtividade agrícola e, consequentemente, gerar desenvolvimento para a região. Contudo, as características locais tiveram influência direta nas ações do CINPRA, sobretudo quanto aos tipos de cultivos, aos tipos de criação animal e às necessidades da mão-de-obra local (GIANNOCARO; BASTOS, 2005).

Isto tem relação com a dimensão D4 (Mecanismo de Imersão Social Cultural) das redes organizacional. As evidências são: a) na agricultura: os projetos de cultivo da mandioca, caju, hortaliças, flores tropicais; b) na criação de animais: ovinos e caprinos; c) capacitação humana: projeto família rural, acompanhamento de técnicos e municipalização da agricultura. Não cabe aqui, detalhar todos os projetos, porém vale destacar o projeto da mandioca, por ser uma raiz nativa e abundante no Maranhão, porém pouco explorada na agricultura, e o da Família Rural, por capacitar a mão-de-obra local sem precisar sair do campo para a cidade (TRINDADE, 1999).

No relatório do "Projeto Conexão Local" os autores Giannocaro e Bastos (2005) afirmam que todos os produtos cultivados na região respeitam as potencialidades locais, ou seja, isso reduz a necessidade de fertilizantes tóxicos, pois a cultura de plantio já vem sendo praticada na região, como é o caso da mandioca e caju. Na maioria dos casos são trabalhadas apenas melhores técnicas de manejo.

Os aspectos regulamentares e constitutivos do CINPRA levam a perceber uma estima em equilibrar os atores quanto aos mecanismos de imersão política, contemplando assim a última dimensão, D5 (Mecanismo de Imersão Social Política). Essa reflexão se justifica, primeiramente, pela equitatividade de contribuição para o consórcio de $0,5 \%$ do Fundo de Participação dos Municípios (FPM), conforme prevê a Lei dos Consórcios 11.107/2005 (BRASIL, 2011). Outra característica que remete essa relação simétrica (equitativa) de poder 
(GRANDORI; SODA, 1995) é a decisão colegiada.

No que se refere à estrutura política, o CINPRA é dirigido pelo Conselho dos Prefeitos, que se reúne a cada três meses (é eleito um presidente e um vice-presidente); as decisões são operacionalizadas pela secretaria executiva. Há também um conselho fiscal e um fórum permanente dos Secretários Municipais de Agricultura, que se reúne uma vez por mês.

Ainda segundo a classificação de Grandori e Soda (1995), o CINPRA pode ser enquadrada como uma rede, além de simétrica e burocrática, pois há um "pacto pela produção e abastecimento" e uma carta de intenções que foi assinada pelos prefeitos de municípios próximos à capital maranhense, em 13 de outubro de 1997.

Diante de um problema coletivo a cooperação e solidariedade entre os atores é fator de considerável peso no sucesso da ação pública. Com os dados coletados, pode-se verificar que os consórcios intermunicipais são um exemplo de redes organizacionais por possuírem características dos quatro mecanismos de imersão social, estrutural, cognitivo, cultural e político.

\section{CONSIDERAÇÕES FINAIS}

O objetivo deste trabalho foi identificar as características que justificam a classificação do CINPRA dentro do conceito de rede organizacional. A categorização pela análise de conteúdo mostrou alguns pontos de semelhança entre as abordagens teóricas com as evidências empíricas. Em caráter exploratório, esta pesquisa cumpre seu objetivo e responde ao problema afirmando que os consórcios podem ser estudados pela análise organizacional de redes, uma vez que compartilham dos mecanismos de imersão social fundamentais, como o estrutural, cognitivo, cultural e político.

As relações entre os municípios consorciados foram identificados como laços fortes por estarem em constante troca de informações e parcerias nos projetos dos consórcios. Nestes laços o CINPRA se mostrou uma rede forte, porém com centralidade no município de São Luís. Isto se explica pelas próprias características de formação do consórcio, que tinha como objetivo básico abastecer e suprir a capital do estado.

Entre os mecanismos de imersão avaliados, o elemento político teve destaque através das relações de poder, pois mesmo o consórcio agindo de forma colegiada, os municípios com maiores quantidade de recursos e maior carência de abastecimento, atraía os interesses mais significativos dos consórcios.

Os outros mecanismos de imersão social, cognitivo e cultural, funcionam como vias de mão dupla. Pois, o consciente coletivo gerado pelo CINPRA influenciou as ações dos municípios e ao mesmo tempo foram influenciadas pelas características locais. Assim, a decisão de aderir ao consórcio esteve ligada à visão de que os municípios poderiam gerar desenvolvimento através de suas potencialidades locais. 
Por fim, este trabalho espera abrir novos caminhos para aqueles que se propõem a dar continuidade aos conceitos abordados, seja baseando-se no mesmo objeto de estudo (CINPRA) e ampliar os resultados alcançados, ou baseando-se em objetos diferentes, capazes de permitir novas visões com uma mesma base teórica.

Ressalvada a limitação de dados, este artigo apresenta de forma inédita no Brasil, um estudo dos consórcios intermunicipais através da abordagem de redes organizacionais, e instiga futuras pesquisas de campo a fim de verificar com maior exatidão novas evidências. Os elementos políticos, econômicos, sociais e ambientais são fatores a serem considerados para que as redes organizacionais possam gerar desenvolvimento, logo, fica como sugestão de pesquisa uma análise do CINPRA através de uma relação teórica entre redes organizacionais e desenvolvimento local.

\section{REFERÊNCIAS}

1. ABRUCIO, Fernando Luiz. A coordenação Federativa no Brasil: a experiência do período FHC e os desafios do governo Lula. Revista de Sociologia Política, Curitiba, 24, p. 41-67, jun. 2005.

2. BARBOZA, Hélio Batista e AROUCA, Francine Lemos. CINPRA - Consórcio Intermunicipal de Produção e Abastecimento. In: BARBOZA, Hélio Batista e SPINK, Peter (orgs.). 20 Experiências de Gestão Pública e Cidadania. São Paulo:Programa Gestão Pública e Cidadania, 2002.

3. BALDI, Mariana. A imersão social da ação econômica dos atores do setor coureirocalçadista do vale dos sinos: uma análise a partir dos mecanismos estrutural, cultural, cognitivo e político. Tese de doutorado em administração, Universidade Federal do Rio Grande do Sul, Porto Alegre, 2004.

4. BARDIN, L., 1997. História e teoria. In: Análise de Conteúdo (L. Bardin), pp. 11-46, Lisboa: Edições 70.

5. BURT, Ronald S. The social stucture of competition. In: NOHRIA, Nitin; ECCLES, Robert G. Networks and organizations: structur, form, and action. Boston, Massachussetts, Havard Business School Press, 1992.

6. BRASIL. Presidência da República Federativa do Brasil. Disponível em: <http://www.presidencia.gov.br/> Acesso em: 20 jun de 2010

7. BRASIL. Serviço Brasileiro de Assistência a Micro e Pequena Empresa. Disponível em: <http://www.sebrae.gov.br/> Acesso em: 20 jun de 2010

8. BRASIL, Senado Federal. Lei Complementar no 11.107 de 2005. Brasília, 2011. Disponível em <http: www.senadofederal.gov.br>.

9. BRASIL, Departamento Nacional de Trânsito - DNIT. Mapa Rodoviário do Maranhão. 
Brasília, 2011. Disponível em <www.dnit.gov.br>.

10. BRASIL, EMBRAPA (Empresa Brasileira de Pesquisa Agropecuária) CINPRA: Maranhão dá exemplo no desenvolvimento regional. Pesquisa Estadual em Foco. Ano V, n.13. Set-Dez. 2001.

11. CALDAS, Eduardo de Lima. Formação de Agentes governamentais locais: o caso dos consórcios intermunicipais. (2007). Universidade de São Paulo, 2007.

12. CRUZ, Maria do Carmo Meirelles Toledo. Consórcios intermunicipais: uma alternativa de integração regional ascendente. In: CACCIA-BAVA, Sílvio, PAULISC, Veronika e SPINK, Peter (organizadores). Novos contornos da gestão local: conceitos em construção. São Paulo: Instituto Pólis, Programa Gestão Pública e Cidadania/FGV-EAESP, 2002.

13. DACIN, M. Tina; VENTRESCA, M. J., BEAL, B. The embeddedness of organizations: dialogue \& directions. Journal of Management, v.25, n.3, p. 317-356, may-june, 1999.

14. FARAH, Marta. Parcerias, novos arranjos institucionais e políticas públicas no nível local de governo. Revista de Administração Pública, 35, 1, 119-134, 2001.

15. GIANNOCARO, Daniela Pereira; BASTOS, Lucas Markowicz. Projeto Conexão Local ICINPRA: Consórcio Intermunicipal de Produção e Abastecimento. São Paulo: FGV, 2005.

16. GRAY, B.; WOOD, J.(1991)."Collaborative alliances: Moving from pratice to Theory". Applied Behavioral Science, Vol. 27- Number 1 and 2- March/June 1991.

17. GRANDORI, Anna.; SODA, Giuseppe. Inter-fim Networks: Antecedents, Mechanisms and Forms. Organization Studies. v.16, n.2. 1995.

18. GRANOVETTER, M.. Economic action and social structure: the problem of embeddedness. American Journal of Sociology, v.91, n.3, Nov. 1985.

19. GRANOVETTER, M. The strength of weak ties. American Journal of Sociology, v.78. n.6, p.1360-1380, May 1973.

20. HALL, Peter e TAYLOR, Rosemery C.R. As Três Versões do Neo-Institucionalismo. Lua Nova, no58, 2003, páginas 193-223.

21. IBGE. Instituto Brasileiro de Geografia e Estatística. Acesso em <http://www.ibge.gov.br/> em 02 de julho de 2010.

22. KAUFMAN, Robert R. A política da reforma do Estado: um exame de abordagens teóricas. In: Revista do Serviço Público, Ano 49; No 01; Jan-Mar ENAP: 1998.

23. LIMA, Ana Paula Gil de. Os consórcios Intermunicipais de Saúde. Cadernos de Saúde Pública, Rio de Janeiro: 2000.

24. NORTH, Douglass. Institutions, Institutional Change and Economic Performance. Cambridge: Cambridge University Press, 1990.

25. MATTAR, Frauze Najib. Pesquisa em Marketing: metodologia, planejamento. 6a Ed. São Paulo: Atlas, 2005. 
26. POLANYI, Karl. A grande transformação. As origens da nossa época. Campus. 4ed. 2000. Obra original publicada em 1944.

27. QUIVY, Raymond; CAMPENHOUDT, Luc Van. Manual de investigação em ciências sociais. Trad. MARQUES, J M; MENDES, M A.; CARVALHO, M. 2.ed. Lisboa: Gradiva Publicações, 1998.

28. RODRIGUES, M.L.A., Construção de redes de proteção dos direitos. Cartilha do curso de Formação de Conselheiros em direitos humanos. Curitiba, 2006

29. SPINK, Peter K. Parcerias com organizações não estatais: São Paulo; Programa de pósgraduação em gestão pública e cidadania, 2006.

30. SANTOS, Lenir. Consórcios Intermunicipais. Aspectos Gerais, suas especificidades em relação ao sistema único de saúde. Secretaria de Políticas Públicas do Ministério de Saúde. 2008

31. SIMON, HERBERT A. Comoportamento Administrativo. FGV. São Paulo: 1967

32. SCHWANDT, Thomas. Três posturas epistemológicas; interpretativismo, hermenêutica e construcionismo social. In: DENZIN, Norman K.; LINCOLN, Yvonna (orgs). Planejamento da pesquisa qualitativa: teorias e abordagens. 2ed. Porto Alegre: ARTMED, 2006.

33. TRINDADE, José Raimundo Barreto. CINPRA - Consórcio Intermunicipal de Produção e Abastecimento. In: FARAH, Marta Ferreira Santos; BARBOZA, Hélio Batista (orgs.). 20 Experiências de Gestão Pública e Cidadania. São Paulo: Programa Gestão Pública e Cidadania, 1999.

34. TORRES, L. A. G. Consórcio Intermunicipal: Estudos, Pareceres e Legislação Básica. Informativo Jurídico do Centro de Estudos e Pesquisas de Administração Municipal (CEPAM) no 11. São Paulo: CEPAM/Fundação Prefeito Faria Lima. 1995

35. TRIVINOS, Augusto N. S. Introdução à pesquisa em ciências sociais: a pesquisa qualitativa em educação. São Paulo: Atlas, 1995.

36. UZZI, B. Social structure and competition in interfirm networks: the paradox of embeddedness. Administrative Science Quartely, v.42, p.35-67, 1997.

37. VAZ, José Carlos. Consórcios Intermunicipais. In:. Dicas no97. 1997, Ação Administrativa 4p. Disponível em <http://www.federativo.bnds.gov.br/dicas $>$.

38. VERGARA, Sylvia Constant. Projetos e relatórios de pesquisa em administração. 5ed. São Paulo: Atlas, 2004.

39. ZUKIN, Sharon; DiMAGGIO, Paul. Structures of Capital: the social organization of the economy. New York: Cambridge University Press, 1990. 